Director de la sección de Literatura del Instituto de Literatura y Lingüística de La Habana «Juan Antonio Portuondo Valdor». Ha realizado numerosos estudios sobre las literaturas española y cubana de los siglos XIX y XX, con especial atención a la obra de Benito Pérez Galdós y la de Fernando Ortiz. Actualmente estudia el período es-

\title{
DE CÓMO FERNANDO ORTIZ SUPO HALLAR UNA MOZA ESQUIVA PARA CIERTO CABALLERO ENCANTADO ${ }^{1}$
} pañol en la obra de Ortiz. Es miembro de la Unión de Escritores y Artistas de Cuba (UNEAC).

\author{
RICARDO VIÑALET
}

En 1909 el escritor español Benito Pérez Galdós (1843-1920) publicó una extraña novela titulada El caballero encantado, cuento real... inverosimil (Pérez Galdós, 1909), que es hoy una de sus menos frecuentadas realizaciones, a pesar de haber gozado de receptividad por la crítica especializada, y por lectores de estratos representativos de cierto nivel cultural. Las valoraciones respecto a ella se han movido dentro de un espectro amplio, de modo que ha resultado controvertida.

Un interesante ejemplo a la altura de 1979 , septuagésimo aniversario de su aparición (por cierto, no agota el interés de los estudiosos, pertinaces en volver constantemente su mirada a la obra hasta nuestros días), es un artículo del profesor Peter A. Bly (Bly, 1979: 20-29). luego de señalar que no es de las más conocidas novelas de Pérez Galdós, se refiere a la diversidad de ópticas asumidas para interpretarla y evaluarla, casi desde su aparición. Menciona a más de una decena de autores e incluye diversas citas, incorporándolas a su propio discurso con el objetivo de fundamentar la tesis que sustenta.

Bly alude a la evidencia de nexos entre el pensamiento de Joaquín Costa - y, por ello, al espíritu de la llamada Generación del 98con Pérez Galdós, incluso en momentos en que cierto pesimismo abatía al destacado reformador. (Una copia dedicada fue recibida por Costa, gesto que agradeció en misiva al autor).

Entre las opiniones coetáneas de la novela introduce una de José María Tenreiro, quien destaca su patriotismo, la apertura de una esperanza para creer en la resurrección de España y la calidad del libro. Transcribe asimismo el encomiástico criterio de Eduardo Gómez de Baquero (Andrenio), escrito unos años más tarde.

De Joaquín Casalduero incluye un juicio que enfatiza el lado social y nacional de la obra. También aparece citado José Schraibman, cuya lectura de El caballero... le conduce a confiar en el papel de la educación como vehículo dinámico regenerador de España. Al acotar a Gustavo Correa vuelve sobre el tema de la cercanía entre Galdós, la Generación del 98 y sus ideales programáticos de una nueva y distinta vida nacional.

Más extensamente recoge Bly conceptos de Julio Rodríguez Puértolas en torno a las convulsas circunstancias hispanas en la fecha de publicación de la novela, y a la inexcusable necesidad de hallar una salida. Con tal prisma la interpreta el aludido investigador, quien insiste en la presencia de Costa dentro de la creación galdosiana, dados el carácter educativo, la denuncia social y la crítica política en ella presentes, subrayándole así implicaciones noventayochistas.

Contrasta, sin embargo, el enfoque del aparato referencial empleado por Bly con la significación que terminará por proponer. Según él, esta novela se resiente de su alcance social debido a que los caracteres - sobre todo protagónicos- pecan de un marcado acento individualista, de sentimientos exagerados acerca de su propia personalidad, de tener una
1

Una versión abreviada, con el título «El caballero encantado en la óptica cubana de Fernando Ortiz: un enfoque sociopolítico regeneracionista e intertextual en 1910", fue presentado por el autor como ponencia en el $6^{\circ} \mathrm{Con}$ greso Internacional Galdosiano: Galdós y el 98, celebrado en Las Palmas de Gran Canaría, España, del 16 al 20 de junio de 1997.

De cómo Fernando Ortiz supo hallar una moza esquiva para cierto caballero encantado RICARDO VIÑALET 
«Mi interpretación acerca del examen que Galdós realiza, a propósito de estos problemas sociales, pudiera ser criticada por su falla en considerar el marco fantástico en que dicho examen se sostiene» [Trad. R.V.].

3

«El caballero encantado puede ser obra de un cansado novelista profesional de sesenta y seis años de edad, pero su tema permanece eternamente relevante para juveniles e idealistas reformadores sociales. Su sutileza de composición es digna de un escritor más joven» [Trad. R.V.].

4

El biógrafo de Galdós y crítico literario Emilio Gutiérrez Gamero - citado por Federico Carlos Sainz de Robles sin precisar la fuente-, al sintetizar el argumento, afirma que "se trata de un curioso capricho [...], en el que tras mostrarnos la vida hueca, falsa, egoísta, inútil y cruel de los que sólo piensan en satisfacer sus pasiones, sus vicios o su bellaquería a costa del trabajo agotador de los humildes (que, a más, es improductivo para èstos), hace que, por arte mágica, esos mismos que malbaratan vida y hacienda absurdamente se vean cara a cara con la realidad $y$, metamorfoseados en pobres gañanes o en vulgares peones de otros trabajos igualmente rudos, aprendan en la práctica lo inicuo de su proceder cuando fueron ri$\cos$ y poderosos, empleándose en labores que exigen esfuerzo y constancia, viendo las miserias y los padecimientos de quienes carecen de todo porque hasta ellos no ha llegado ni el bien de la instrucción, a que todos tienen derecho, ni el cuidado más elemental por mejorar las condiciones de vida, ni la protección que les es debida, contra los abusos de todo género que con ellos cometen los eternos mangoneadores pueblerinos, que los tratan más como a rebaño que como a seres humanos» (Sainz de Robles, 1951: 221).

De cómo Fernando Ortiz supo hallar una moza esquiva para cierto caballero encantado

RICARDO VIÑALET vida en lo esencial guiada por las apetencias sexuales, y de atender más a los aspectos materiales de la existencia que a los espirituales. Según Bly, se produce así un debilitamiento en la intención social regeneradora. Los elementos apuntados le conducen a valorar más la obra como de propuestas morales y no sociales.

Cierto es que en $E l$ caballero... se percibe una novela de planteamientos éticos, aunque el criterio de Bly deviene algo redundante, si se tiene en cuenta que la ética es hecho y disciplina sociales, colectivos, a pesar de que se asuma individualmente. La moral se establece desde parámetros socialmente condicionados, por ende una obra de reflexión ética lo es también -y por ellode reflexión social.

El profesor Bly llega, quizás, a tal interpretación porque ha partido de otra previa, equivocada a mi modo de ver: asume $E l$ caballero... con un enfoque demasiado literal, como si se tratase de analizar una más de las creaciones galdosianas donde el autor es convencionalmente realista. Por consiguiente, le es imposible acceder a otras lecturas más en correspondencia con la tónica fantástica y la naturaleza simbólica que ella tiene. Lamenta, incluso, que la ficción resulte increíble. No logra situarse desde el prisma de la fantasía, hecho explícito además por Galdós en el subtítulo. La dimensión social de $E l$ caballero... es muy evidente si el lector se ubica en la inverosimilitud aparencial. El profesor parece alcanzar conciencia de la fragilidad de su análisis cuando afirma: «My interpretation of Galdós examination of these social problems could be criticized for its failure to take into account the fantastic frame in which the examination is held $»^{2}$ (Bly, 1979: 24).

El catedrático de Queen's University, habiéndose colocado en una inquietante literalidad, sostiene que la novela resulta superficial e insuficiente en sus propuestas. El único sostén ajeno citado en su argumentación es el siguiente de Hans Hinterhaüser: «Desde el punto de vista artístico, habría que hacer muchas objeciones a esta novela; una gran cantidad de motivos secundarios ahogan el tema principal, de modo que surge algo así como un confuso resumen de las experiencias propias de la vejez de Galdós» (Bly, 1979: 28).
Tal vez comprendiendo al final que ha ido demasiado lejos, intenta ser conciliador en la conclusión de su ensayo, y dice: «El caballero encantado may be the work of a tired sixty six-year-old professional novelist, but its theme remains eternally relevant to youth's idealistic social reformers. Its subtlety of composition is worthy as a younger writer» ${ }^{3}(\mathrm{Bly}$, 1979: 28).

En definitiva, está reconociendo tanto la significación social de El caballero... como la astucia de creación, la validez artística de la obra y hasta el vigor juvenil que de ella emana.

Valga la muestra presentada para ilustrar cómo a pesar de la diferencia de matices con que El caballero... haya podido ser recibida por la crítica, existe consenso en cuanto a las intenciones que animaron a Galdós por plantear una meditación en torno a España, su historia, su presente y perspectivas.

La obra re-edita, no sin ironía, el aire de los viejos relatos caballerescos, donde encantamientos y otras circunstancias de esta suerte devienen lugar común. Hay también espacio para diversas modalidades narrativas de los siglos XV y XVI, tales como la novela pastoril, sentimental y picaresca. Dadas esta capacidad aleatoria y la índole de la fábula, de inmediato se percibe el aura quijotesca, en la cual - tras una aparente inocencia de las peripecias hilvanadas - se agazapa el objetivo de más trascendentes pensamientos. Así Pérez Galdós inscribe su creación desde claves simbólicas y desarrolla un discurso literario parabólico en torno a las particularidades de su tiempo y al estado de España. No obstante, en El caballero... se advierte la ausencia de la socarronería cervantina, su humorismo, capacidad para la burla sutil y la parodia. Esta es más iracunda, severa y explícita. Desde la concepción de los personajes hasta el subtítulo transparentan las intenciones galdosianas.

Por otra parte, la formulación real... inverosimil es útil para insistir (incluso hoy) en que no puede circunscribirse el realismo a determinado método de creación, aspecto muy importante para mostrar la inconveniencia no sólo de entender el realismo casi unidimensionalmente, sino de encasillar a Galdós en procedimientos literarios muy específicos del siglo XIX. En El caballero... 
hay un momento en que el protagonista abandona «el concepto de lo real para volverse al de lo maravilloso» (Pérez Galdós, 1909: 240). Poco después, desde lo maravilloso comprenderá que se encuentra en otra zona de lo real, muy próxima a la nombrada, cuarenta años más tarde, "lo real maravilloso» por Alejo Carpentier, desde luego con perspectiva diferente. Quizás en esta novela de Galdós pudiera hablarse de lo maravilloso real.

De hecho, el español tampoco descubrió el asunto, pues El caballero... se factura con antecedentes aportados ya en El Quijote, homenaje presumiblemente consciente a quien de modo igual maravilloso y real fue capaz de proponer un hondo análisis de su tiempo y lugar.

El tema, obsesivo en la literatura del último cuarto del siglo XIX, se hizo agónico alrededor de 1898 y en los años inmediatamente posteriores.

Ante la difícil situación en todas las esferas de la vida nacional, la creciente conciencia de que el país se rezagaba con respecto del resto de Europa; que el poderoso imperio colonial era ya simple memoria, empezó a delinearse una actitud entre la intelectualidad que llevaba como divisas el pesimismo, la insatisfacción y el espíritu crítico. En el terreno de las ideas ocuparían espacios importantes Hegel y, sobre todo, el positivismo. Se conformaba el juicio colectivo de que, ante el descalabro nacional y la decadencia correspondiente, era preciso encontrar un remedio que revirtiera el proceso.

El krausismo constituyó un esencial movimiento ideológico abanderado de la renovación española. Como se conoce, tomó su nombre del filósofo alemán Christian Friedrich Krause y le dio inicio Julián Sanz del Río. Seguidores suyos le imprimirían notable impulso. No obstante, el peso no recayó en el terreno estrictamente filosófico, sino en el educacional, que se consideró la vía inmanente para la transformación. Devino plataforma expresiva del rechazo a las circunstancias en que se vivía. Continuadores de Sanz del Río, entre los que descuellan Francisco Giner de los Ríos y Joaquín Costa, fueron autores de textos impregnados del ansia modificadora y estuvieron imbuidos de hondo espíritu crítico.
Han sido justamente llamados los krausistas educadores de la España contemporánea, ya que junto al valor que en sí mismos tienen; al de constituir otra vuelta de tuerca para el movimiento reformista del siglo XVIII y, a la

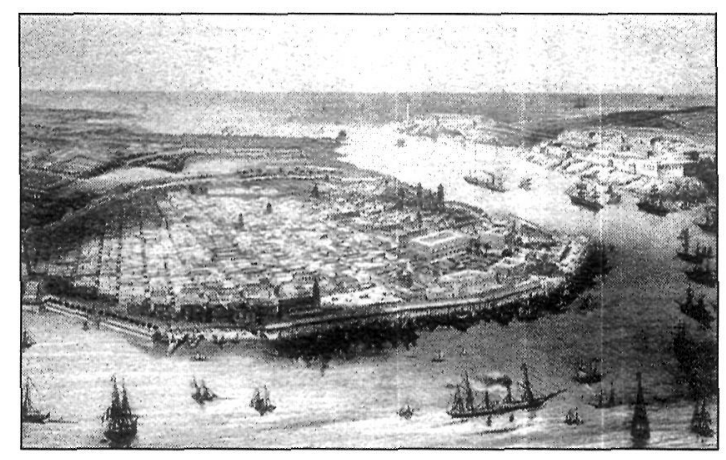

Bahía de La Habana. Litografía de Assilineau, siglo XIX. vez marcar el preámbulo de la llamada Generación del 98, asimismo son fundacionales para otros alientos que se vinculan a las ideas y a la creación literaria más adentrado el siglo XX. El krausismo tiene mucho que ver con el afán de mejoramiento axiológico para varias promociones de españoles. En consecuencia, llega a ser un enlace de angustias, aspiraciones y juicios críticos de hombres anteriores al siglo XIX con los del siglo XX. En rigor, el complejo de decadencia puede rastrearse en la literatura española, al menos, desde el siglo XVII con Cervantes y Quevedo. En el XVIII es perceptible en figuras como Gaspar Melchor de Jovellanos y José Cadalso, entre otras.

Coincidentemente con el krausismo sobreviene, como es sabido también, el período literario realista-naturalista, etapa en la que comienza Pérez Galdós su carrera de escritor. Atípico resulta su caso, pues si cronológicamente habría que situarlo en la promoción inicial, su obra la rebasa por estar más cercano en los temas y en el espíritu a la segunda, aunque su trayectoria, técnicas artísticas y concepciones lo llevan a ser hombre y autor contemporáneo.

Verdaderamente es en el año 1898 cuando sobreviene el clímax. La pérdida de $\mathrm{Cu}-$ ba, Puerto Rico y Filipinas, más el ya apuntado proceso de deterioro económico y sociopolítico, harían que ese instante histórico fuese denominado el desastre. Constituyó una crisis de las conciencias. En muchos españoles quedó un amargo sabor, incluso en algunos que no se caracterizaron por el conservadurismo. No hay que inferir en todos los lamentos por la derrota una actitud imperial o imperialista, sino que -en medio de serias contradicciones de múltiple signo- vieron en la pérdida de las colonias 
la manifestación suprema del descalabro total de su patria.

La denominada usualmente Generación del 98 emerge, pues, como una suerte de movimiento que, a partir de cuestionarse la situación nacional en todos los órdenes, cobra un sesgo marcadamente intelectual y posee manifestaciones de gran importancia en el terreno literario, ámbito en el cual desarrollaron gran parte de su pensamiento crítico y afán renovador. Por ende, la temática más abordada tuvo que ver con el estado de insatisfacción, con la crisis global española, con la corrupción, la intolerancia religiosa, la rigidez escolástica en las formas de vida, el conformismo, la mediocridad: reaccionaron contra todo ello adoloridos por su país. Al propio tiempo desearon abrirse a las más novedosas corrientes del pensamiento europeo, esto es, se trazan como objetivo la europeización de España: europeizadores con pasión española, ya que volvieron los ojos de igual manera a su historia, intentando comprender los orígenes de los males. Su mirada se detuvo, atenta, en los campos, aldeas y pueblos, en los paisajes, en el folklore, en lo tradicional, en su identidad.

Desde un punto de vista estrictamente literario, se planteó una voluntad de estilo dentro de la diversidad de sus integrantes, que se vinculaba al interés de dignificar el espíritu hispano, al afán regenerador, a una nueva españolidad.

Contexto ineludible de la Generación del 98, pero no sólo de ella, es el llamado regeneracionismo. Con frecuencia éste queda circunscrito a movimiento ideológico desarrollado en España a consecuencia del desastre de $1898 \mathrm{y}$, en tal sentido, su alcance se limita a tentativas de modificar la vida política del país.

Por todas las consideraciones que se han venido exponiendo, puede extenderse en tiempo y espacio el ámbito regeneracionista, incluso llevarlo más allá de las fronteras hispanas. Si regenerar implica el restablecimiento o la mejoría de algo que ha degenerado; si presupone en seres humanos y en colectividades el abandonar hábitos o conductas reprobables, puede coincidirse en que la crítica a la sociedad española se vislumbraba con determinada sistematicidad desde, casi, los inicios del último cuarto del siglo XIX, y aun antes con menor coherencia.
El movimiento regeneracionista apunta a las ideas y clama por la reconsideración de la vida política; no obstante, su esencia va más lejos y se expande totalizadoramente desde una asunción ética, de apego a los genuinos valores de la espiritualidad hispana, de su cultura, con marcado interés por la modernización de las estructuras en el país y en las mentes. Su presencia es impactante en el pensamiento, pero también en la literatura. Ver$\mathrm{dad}$ es que el regeneracionismo se delinea con precisión alrededor de 1898, aunque su aliento llega desde otros tiempos, por lo cual es factible asumir el concepto con sentido amplio y perspectiva dialéctica (Viñalet, 1996: 27-29).

Benito Pérez Galdós, creador que no forma parte del grupo conocido como Generación del 98, a pesar de ciertas coincidencias, es un magnífico exponente de escritor regeneracionista, no sólo en la obra producida durante los años que vivió del siglo XX, sino desde su primera época. Baste recordar Doña Perfecta (1876) y La familia de León Roch (1878). Los Episodios Nacionales, que se inician en 1873, con certeza no escapan al intento de reflexionar sobre España, en este caso procurando integrar lo novelesco y una interpretación de la historia. La literatura galdosiana, desde el principio, colocó a los españoles ante el tribunal de sus propias conciencias (Viñalet, 1984: 100-129).

El conservadurismo, el catolicismo intolerante y, en general, las fuerzas retrógradas sintieron - con razón - en Galdós a un enemigo. Fue éste hombre y escritor de preocupaciones constantes por los problemas nacionales, tanto aquellos de índole política como los de naturaleza ético-sociales, dentro de los que se destaca el interés por la historia del país, en especial la del siglo XIX.

Su obra, que alcanza el carácter de monumentalidad por la amplitud, variedad y profundidad, sobresale por el mensaje de que es portadora: el rechazo de lo injusto, lo abusivo y lo arbitrario. La irracionalidad de los tiempos por él vividos llegó a ser tan grotesca como algunas piezas de Goya, y Galdós llevaba a un pintor dentro de sí.

Sus personajes, capaces de alcanzar la representación de vicios o de virtudes, son dados por el autor desde lo hondo de sus sentimientos de amor, caridad y verdad. No
De cómo Fernando Ortiz supo caballero encantado RICARDO VIÑALET 
devienen meras alegorías porque se hallan en relación dinámica con el medio. De ahí que haya creado un genuino universo de caracteres. Fue Pérez Galdós baluarte, tenaz defensor del pueblo, de lo verdaderamente popular, que se convierte en esencia de su creación artística.

La óptica realista, progresiva que guió su vida y su producción literaria, estuvo matizada con ciertos idealismos utópicos en las aspiraciones reivindicativas con que soñó. Es necesario buscar la esencia de los anhelos galdosianos en las ideas de la tolerancia, del amor y la comprensión; en esa tríada - pensaba- se encontraría la senda para la conciliación de las pugnas nacionales. Deseó una armonía sociopolítica e individual entre cada hombre, apoyada en la justicia, en modos de distribución menos desiguales para la riqueza; ansiaba que cada ser humano pudiera ser expresión libre y sana de sí mismo, sin perjuicio de otros. Bellos sueños, estrellándose contra una realidad que no admitía conciliaciones. Escapaba a Galdós cómo las contradicciones, si son antagónicas, no cejarán hasta el estallido, muy especialmente en las condiciones españolas del siglo XIX, y aun del XX como se ha encargado de probarlo la historia en que el escritor tanto hurgó.

El caballero encantado, novela no de vejez intelectual, sino de concretas y reales meditaciones angustiadas en hombre de espíritu sensible, es consecuente con la trayectoria vital de su creador. Por ello, Sainz de Robles, delicado, respetuoso y fascinado, considera: «Es una narración deliciosa. [...] El simbolismo es siempre el mismo: la historia, España [...] Siempre fue Galdós un apasionado español. No poco si afirmo que el más español de todos los grandes escritores del siglo XIX. Español con orgullo inmenso de serlo y con optimismo jamás entibiado en futuros destinos españoles. Con los años, el patriotismo incondicional de Galdós se fue exaltando hasta límites que causan una emoción vivísima. Y es en la última serie de los Episodios Nacionales y en El caballero encantado [...] donde con más ahínco hace su inmensa profesión de fe. Ciego, torpe, un poco desengañado de todo, se refugia en su todo: España. Y la ve mejor que nunca. Y mejor que nunca la penetra y la entiende» (Sainz de Robles, 1951: 221-222).
Si deliciosa es una palabra que emplea Sainz de Robles para calificar la novela, varias décadas antes el cubano Fernando Ortiz la llamaría $d i-$ vina e, inspirado por ella, en 1910 publica una versión libre y americana que titula El caballero encantado y la moza esquiva (García-Carranza, 1970: 36 y 71).

La simpatía sentida por Ortiz hacia El caballero... obedece tanto a razones literarias como extraliterarias.

En el primer caso, existe amplia referencia de cuánto admiraba a

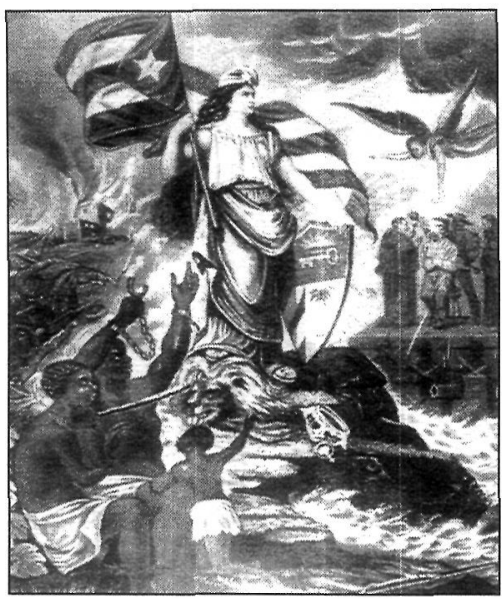

Alegoría a la República cubana. Pérez Galdós (Ortiz, ¿1911?). Reconoce la maestría del escritor canario para crear en esta oportunidad una novela fantástica, sobrenatural, especie de jornada onírica donde el tiempo marcha caprichosamente y desplaza a los personajes por diversos planos, no sólo temporales, sino espaciales, envueltos en magia y misterios. Ha gustado de la propuesta simbólica - esencial en el relato-, pues le incita a la diversidad de lecturas y él asume una interpretación. Desde ella elabora suversión libre y dará un consejo al lector, según Ortiz válido para el acceso al original y, por ende, a la traducción que él emprende: «Avive el entendimiento el que quiera seguir leyendo si no es ducho en simbolismos, que el maestro Pérez Galdós nos exige a todos en este caso imaginación cautelosa al par que avispada para darnos justa razón de lo que se descubre en los repliegues de su lenguaje y se transparenta tras el velo de las personificaciones y sucesos, a veces borrosos, por el misterio que - para mayor atracción- los rodea como neblina. El caballero encantado debe leerse dos veces, una al correr de la vista sobre las páginas, otra más pausada y entre líneas toda ellas» (Ortiz, ¿1911 ?: 256).

Las consideraciones extraliterarias radican en la temática y en su significación, dadas las específicas circunstancias en que fue escrita, y en las que se produce la recepción de don Fernando. Como El caballero encantado plantea el asunto de la regeneración de España desde el prisma sociohistórico y ético, toca de lleno en preocupaciones suyas en esos años primeros del siglo, por su incidencia en la vida cubana. De ese mismo carácter es su interpreta-

De cómo Fernando Ortiz supo hallar una moza esquiva para cierto caballero encantado

RICARDO VIÑALET 
ción e, inevitablemente, con tal sentido - desde la otra orilla del Atlántico y enfoque americano- escribiría El caballero encantado y la moza esquiva.

El descalabro español y nuestra gesta independentista se hallan en el centro del problema. En Cuba, el 98 hubo de tener una violenta repercusión. Baste apuntar que la noción del desastre fue también para nosotros una dolorosa realidad. Los ideales y luchas liberadoras desembocaron en frustraciones gigantescas. El final del dominio español coincidió con la intervención norteamericana y sólo en 1902 nació la república, como se sabe distante de los sueños y mutilada por la Enmienda Platt, que nos condicionaba a los intereses y apetencias del vecino poderoso. Tal fue el signo de aquellos primeros años. La historia es prolija en recoger las disputas civiles, revueltas militares, la segunda intervención armada estadounidense, la corrupción social, administrativa y política. Duros tiempos en que ganaron terreno el escepticismo y el desengaño.

Núcleo de las preocupaciones y acción de cubanos ilustres fueron el mantenimiento de la identidad nacional, de la nación misma; la conciencia de que era necesario remediar la crítica situación; la comprensión de lo impostergable de indagar acerca de la identidad cultural, esto es, quiénes, qué y cómo somos. Era un modo de encarar el reto.

Dentro de los primeros esfuerzos de Fernando Ortiz, no pocos se dirigieron al autoexamen, al autoconocimiento del cubano (Serrano, 1987). Asimismo emprendió una cruzada en pro de la dignificación ciudadana en aquella república artificial y exhausta desde el mismo 20 de mayo de 1902, cercenada en la soberanía, urgida de emprender un camino largo y arduo de ascensión ética, social y política. Ortiz recogió el guante; percibió que por ahí se marcaba un rumbo para alcanzar los objetivos: regeneracionismo desde la derrota, la pobreza y la identidad, tan afines evaluó las circunstancias cubanas y españolas. Un regeneracionismo desde la otra linde, transculturado.

La inquietud renovadora, asimilada creativamente en sus estancias españolas, devino génesis del quehacer sobre Cuba, sus problemas y su cultura. Las confluencias que en su obra, de principio a fin, se observan entre re- generacionismo, identidad nacional y cultura son la espina dorsal de todo Fernando Ortiz.

Pero entre ciertos regeneracionistas hispanos, había algunas zonas oscuras y sobre ellas don Fernando se manifestó muy crítico. Una fue el panbispanismo, verdadero intento neocolonialista por someter a Hispanoamérica a la tutela de la ex-metrópoli. Derrotada completamente en el terreno militar, cruzó por la mente de algunos la idea de que España volviera a imperar en las antiguas posesiones mediante el ejercicio de influencias y de privilegios económicos. Maltrecha y rezagada, ansiando europeizarse para hallar una senda emergente de salida a sus males, con elevados índices de analfabetismo e incultura, así como con agudos conflictos sociopolíticos, pobre modelo habría de ser para las repúblicas hispanoamericanas. Desde tales presupuestos rechazaba Ortiz el frenesí panhispanista.

No pocos voceros de esa tendencia elaboraron un discurso oportunista. Llegaban a argumentar que, o España ejercía su misión tutelar sobre Hispanoamérica, o ésta caería bajo el hegemonismo norteamericano. Así el viejo imperio estaría llamado a rescatar a sus hijas de las fauces del imperialismo yanqui, joven y pujante. Claro que nada iba a impedir que Estados Unidos se lanzara a convertir a Nuestra América en su traspatio. Las intenciones y hechos están a la vista y en la memoria. La maniobra panhispanista sólo ofrecía optar entre dos imperialismos.

Fernando Ortiz, como otros cubanos lúcidos, comprendió de qué se trataba. Al respecto abunda en La reconquista de América; reflexiones sobre el panbispanismo y en Entre cubanos: psicología tropical, libros que agrupan textos diversos, en su mayoría aparecidos en publicaciones periódicas entre 1905 y 1913, muchas veces al calor de polémicas.

Encarando la esencia del dilema en sus formulaciones polares, insistirá en el rumbo de las soluciones: «Engendros anémicos de un imperialismo que moría, hemos seguido embrutecidos en la modorra tropical, de la que despertaremos tarde, cuando otro imperialismo que crece nos haya arrastrado en su torbellino. [... ] Sólo una civilización intensa y difundida podría salvarnos; siendo cultos, seríamos fuertes. Seámoslo» (Ortiz, 1913a: 77- 
78). La salvación desde la cultura es la propuesta, de clara ascendencia krauso-positivista, estandarte ideológico del regeneracionismo y del grupo dado en llamar Generación del 98. Sin embargo, en esta versión cubana que Ortiz plantea está clamando por la existencia de la nación, sosteniendo el escudo de la identidad nacional desde la cultural.

Don Fernando, con nítido concepto de esa, nuestra identidad, no hilvanaría ideas apendiculares de la ex-metrópoli, sino acerca de la importante tarea que a ella correspondería. Por tanto, incita: «Esto es lo que debería hacer España, traernos cultura, mucha cultura, porque cuando España impere por su cultura y por el genio científico de sus hombres nuevos, entonces, entonces sí, la América entera será verdaderamente española, hasta la que hable inglés, porque en los tiempos que corremos la civilización es la que une a los pueblos» (Ortiz, 1913a: 107).

El pensamiento estratégico de Ortiz busca la integración de las repúblicas hispanoamericanas, lejos de los intentos panhispanistas y tratando de evitar la absorción por parte de los Estados Unidos. Es bien explícito: «Si nos convencemos y conseguimos llevar a la realidad [...] la asociación para la lucha, podremos algún día presentar un bloque mental iberoamericano bien unido, resistente y bien caracterizado" (Ortiz, 1913a: 17-18).

He aquí, pues un conjunto de hechos que motiva el surgimiento de El caballero encantado y la moza esquiva.

El título pero, sobre todo, el subtítulo versión libre y americana, pudieran conducir inicialmente a pensar en un Fernando Ortiz narrador. Existen, de otro lado, como antecedentes un cuento escrito en su etapa de estudiante de bachillerato, publicado en $\mathrm{Me}$ norca, así como el folleto Principi i prostes (Ortiz, 1895), de artículos costumbristas, en menorquín, que por su índole incorpora elementos de la narrativa (García-Carranza, 1970: 15).

Si tal óptica fuera asumida, El caballero... y la moza... requeriría de juicios específicamente literarios y la obra - en tanto novelacarecería de valores para destacarse en el género. La esencia del fenómeno está en que Ortiz no pretendió novelar. Se trata de una interpretación, de una reconsideración, de una reescritura que persigue el objetivo de desarrollar un discurso político regeneracionista y opuesto al panhispanismo. No por otra razón forma parte de La reconquista... Ha manipulado a la literatura; juega con ella y la resultante es una suerte de sátira con ribetes paródicos, lo cual sí demuestra en don Fernando la conciencia estética (algo, por demás, muy habitual en su obra). De esto a presumir intentos de creación nove-

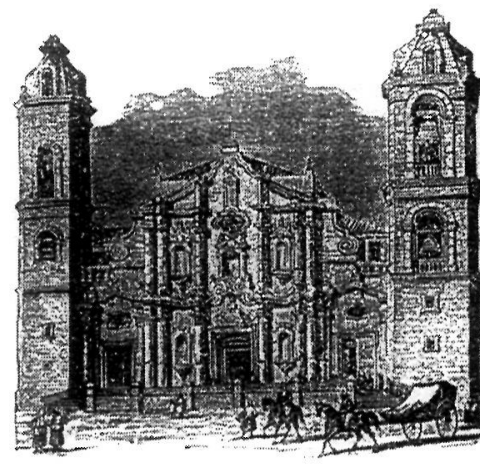

Catedral de La Habana (grabado del siglo XIX). lesca hay una distancia larga.

Aún más, Ortiz es bien transparente al declarar sus pretensiones. En el prólogo, cuando alude a la obra de Pérez Galdós, expresa: «Buscad el libro y leed la más curiosa e instructiva historia española de estos tiempos, mas [...] hela aquí, monda y lironda, sin los afeites y colores que le diera el esclarecido ingenio de su primer narrador» (Ortiz, ¿1911?: 255-256).

Podará, nos ha dicho, ha de sintetizar y simplificar porque su obra es otra e insta al lector a procurarse la original, de manera que esté en capacidad de acceder al texto matriz, diferente del suyo, donde han de constatarse hasta alegatos complementarios o, llanamente, diferentes. Luego declara: «Aquí el propósito. El autor de estas líneas somete a su fantasía la magistral novela [...] y la interpreta desde puntos de vista americanos, subrayando los episodios y dichos principales que más pudieran interesar a los hijos de América» (Ortiz, ¿1911 ?: 256). En la más literal y sabrosa acepción del término estamos ante un texto tendencioso.

En El caballero encantado y la moza esquiva se observan tres partes: un corto prólogo con claves interpretativas; la versión propiamente dicha de la novela galdosiana, cuyos capítulos y títulos no se ajustan al primario; y un epílogo que trasciende los criterios del escritor hispano.

De la primera se ha tratado. En la segunda, la narración queda reducida en, aproximadamente, dos terceras partes y el número de capítulos desciende de veintisiete a catorce. En nota al pie de página del Capítulo I, Ortiz explica: «Ni los capítulos de esta traducción, ni sus títulos, corresponden a los respectivos del original español» (Ortiz, ¿1911 ?: 257), o sea, insiste en su libre hacer, en llevar al esqueleto
De cómo Fernando Ortiz supo hallar una moza esquiva para cierto caballero encantado

RICARDO VINALET 
Ortiz ubica el parlamento en el Capítulo II, mientras Galdós lo hace en el |il, muchos más extensos éstos que los de la versión. Cotejado con Obras Completas de Benito Pérez Galdós, tomo VI, ed. cit., pág. 232. Los restantes cotejos se realizan sobre la misma fuente).

6

Cotejo: pág. 233 la anécdota, muchas veces glosando en pocas palabras lo que en Pérez Galdós resulta prolijo, y también volviendo a llamar la atención acerca de su papel de traductor, vale decir, de interpretador.

El tono de esta glosa llega a ser humorístico e irónico, y don Fernando revela una estupenda capacidad para caracterizar personajes y situaciones, a veces mediante el empleo de simples adjetivos: «Un amigo conservaba Tarsis decadente. Pegadizo, sablista y sabio machacón era D. José Augusto del Becerro, muy metido en legajos e infolios, apasionado por rompecabezas heráldicos, maniático por erudiciones históricas, rebuscos de archivos y bibliotecas, pápiros, pergaminos e incunables, hasta caer de bruces en la curiosa chifladura de llamar hermanas queridas a la Edad Media, a la de Piedra, a la Época Fenicia y a la Romana y a muchas otras hijas de la prolífica Historia Española» (Ortiz, ¿19 11?: 259).

El fragmento del párrafo transcrito lleva a Pérez Galdós varios capítulos de su novela, con diferente punto de vista narrativo, ya que no enjuicia las actitudes del personaje. Ortiz, de otro lado, asume una visión del Sr. Becerro que, en medio de una humorada, entrega ya hecha al lector.

Hay oportunidades en que don Fernando convierte al propio Galdós en participante de la versión, con el mismo espíritu que se aprecia en el ejemplo anterior: «En la fecha en que la narración comienza, cuando Pérez Galdós entró en tratos con Don Pueblo, digo, con Don Carlos de Tarsis, éste se sentía desesperado, tristón, pesimista...» (Ortiz, ¿1911?: 259-260).

También emplea el recurso de citar textualmente pasajes, relativamente breves, de la obra original, como apoyatura de su enfoque y de los matices, un verdadero trabajo de intertextualidad. El Tarsis escéptico se lamenta: «El teatro clásico, con su Lope y su Tirso, me carga también y siempre que voy a una función de esa clase, llevo la mala idea de descabezar un sueño en mi butaca. Una obra del teatro clásico se titula como debieran titularse todas: La vida es sueño. Digo y repito con pleno convencimiento que no tenemos agricultura, como no tenemos política ni hacienda. Todo esto aquí es puramente nominal, figurado, obra de monos de imitación, o de histriones que no saben su papel. Aquí no hay nada. Cuanto veis es bisutería procedente de saldos extranjeros» ${ }^{5}$ (Ortiz, ¿1911?: 261).

En otro fragmento, de nuevo citando a Galdós, arguye el personaje: «iTrabajar! ¿Para qué? Los chispazos, los resplandores de fuegos fatuos que vemos en literatura, en artes gráficas y en algún otro orden de la vida intelectual, no nos invitan a que trabajemos. Todo nos llama al descanso, a la pasividad, a dejar correr los días sin intentar cosa alguna que parezca lucha con la inercia hispánica. Si me pusieran en el dilema de trabajar o perecer, yo escogería la muerte. El español que en este final de raza posea en renta, debe sostenerla y aumentarla si puede. Vivir bien mientras la vida dure, y mientras en la lámpara del bienestar no se consuma la última gota de aceite. No trato de presentarme como superior a los demás. Soy el peor, soy el último perezoso, el último sacerdote o monaguillo de la inercia. Mi único mérito está en la brutal sinceridad de mi pesimismo» ${ }^{6}$ (Ortiz, ¿1911?: 263).

Luego que Tarsis se ha prendado de una bella sudamericana, ella lo rechaza y sobrevienen nuevas peripecias, se produce el encantamiento del protagonista. El cínico, holgazán, pesimista y ricachón se trueca - por arte de magia - en pobre mozo que ha de pasar vicisitudes innumerables y éstas le harán comprender cuán vacía y decadente, explotadora, fue su vida anterior. Esto le llevará a reevaluarla y a asumir una posición activa, regeneradora, comprometida con los humildes a quienes tanto había despreciado y sometido.

En el proceso desempeña papel fundamental un personaje llamado La Madre, maga con poderes limitados, suerte de reencarnación de la maltrecha hispanidad. En sus manos estará el hechizado hasta el completamiento de su transformación positiva.

A lo largo de un diálogo que sostiene Tarsis (devenido el pelagatos Gil) con La Madre, éste enumera un grupo de defectos que caracteriza a los españoles de la decadencia. Empero su óptica, aun consciente de los desafueros cometidos por los ricos contra los pobres, no pretende subvertir el status, sino que reclama a los poderosos que lo sigan siendo, aunque ricos buenos, para que los pobres 
lo sean menos y también buenos: dar sin quitar a nadie, así sea esa riqueza resultante de la más abusiva expoliación. Aquí Ortiz vuelve a anotar a Galdós, en punto altamente revelador de tales idealizadas concepciones: «Somos iguales, y el pobre y el rico, el plebeyo y el noble, nos hallamos en venturosa fraternidad; por ella vivimos» ${ }^{7}$ (Ortiz, ¿1911 ?: 275276). Si bien esta sublimación no forma parte de las opiniones de don Fernando, él respeta la intención sana que la provoca, no polemiza y cuando prosigue el relato, ya con sus palabras, comenta: «Donosa lección [...] que podría aprovecharnos por igual a todos, al hispano hablador para su vida nueva trabajosa y dura, y al americano parlero en su labor de esperanzas» (Ortiz, ¿1911?: 276). Va intercalándose de esta manera la proyección americana con que ha deseado elaborar su versión.

Sin embargo, en ocasiones no puede menos que disentir, sobre todo cuando de la americanidad se trata: la amada de Tarsis sufre también de un hechizo que la transforma de Cintia en Pascuala; de hermosa sudamericana capaz de rechazar a Tarsis por sus defectos, en una maestra rural de España. Ortiz lo admitiría si se tratara, simbólicamente, de mostrar cuánto han de aprender los hispanos de sus excolonizados, pero no deja pasar la oportunidad para el señalamiento irónico y humorístico: «Si de Tarsis sabemos desaciertos y majaderías que a la Madre inspiraron un encantamiento por bien, no sabemos que la ingenua Cintia tuviese mataduras [...] ni que se hubiese apartado del bien y que al bien hubiese de volverla el amor a la Madre común. [...] Por lo que quizás este largo capítulo estaría mejor titulado así: Donde aparece una Pascuala y donde el encantamiento o no es o es injusto o es sólo del caballero» (Ortiz, ¿1911 ?: 287). Un fustazo, pues, a cualquier atisbo panhispanista.

El cese del hechizo sólo se producirá cuando La Madre considere cumplida su misión regeneradora; en el espíritu galdosiano ello tendrá lugar dentro de un clima de concordia: Cintia y Tarsis se amarán, serán felices y sobrevendrá un hijo común. Se imponen, especialmente a estas alturas, las leídas entre líneas que Ortiz recomendaba en su prólogo. ¿Escaparía realmente Pérez Galdós a ejercer la misión tutelar?
De modo que don Fernando necesita de un epílogo netamente americano, en que ya prescinde del texto primigenio para internarse en su discurso propio, sin perder el aura novelesca. Adoptará la forma epistolar y un simbolismo casi alegoría.

Se inicia con la Carta intima de América Andina a su bermana menor Juanita Antilla, fechada en Buenos Aires, significativamente, el 25 de mayo de 1910. La remitente se lamenta por la escasa comunicación entre ambas: «Estamos tan lejos y son tan tardíos los correos, ¡la familia está tan desparramada! Pero aunque con distinto apellido, hermanas somos al fin por parte de madre y justo es que nos queramos y contemos nuestras cosas» (Ortiz, ¿1911?: 321). Desde el principio ha establecido en su epílogo el concepto del iberoamericanismo, de su necesidad y llama a la unión.

Dice la hermana mayor: "Te supongo enterada por nuestro antiguo amigo Don Benito Pérez Galdós, quien a pesar de no conocernos de vista sabe de viejo nuestras penas y alegrías [...], de la nueva locura que se ha apoderado de Carlitos de Tarsis» (Ortiz, ¿1911?: 322). Añade que el guapo mozo se ha presentado por aquellas tierras, "rondándonos la reja, hablando nuestro lenguaje y diciéndonos palabritas más dulces que la miel» (Ortiz, ¿1911 ?: 323).

La carta de América Andina resulta así una llamada de alerta sobre el intento neoimperialista del panhispanismo, dirigida a Juanita Antilla, quien no pudo zafarse hasta muy tarde del autoritarismo maternal. Le cuenta de los celos de Tarsis ante otros pretendientes, en especial Samuel Johnson, y concluye atribulada: "Aconséjame tú. Dime si debo rendirme al infeliz enamorado, si he de despedir a mis amigos y admiradores, y si debo renunciar a mi rica libertad de rica hembra por una unión, casamentero antojo de nuestro pobre y alicaído primo» (Ortiz, ¿1911 ?: 329).

Diáfano en sus objetivos y preocupaciones, incluye don Fernando a continuación la réplica confidencial a la hermana mayor. Reveladoramente escrita en Baracoa y, no menos, el 4 de julio, la carta se inicia con un nunca olvidada hermana América y luego de felicitarse por haber recibido sus noticias, comenta: «Hoy estamos de fiesta y jolgorio por estos barrios con motivo del cumpleaños de un vecino muy bullanguero que tú
7

Cotejo: pág. 256.
De cómo Fernando Ortiz supo hallar una moza esquiva para cierto caballero encantado

RICARDO VIÑALET 
Una lectura desde esta perspectiva puede hacerse de La reconquista... y de Entre cubanos..., por mencionar sólo dos ejemplos aludidos reiteradamente.
De cómo Fernando Ortiz supo hallar una moza esquiva para cierto caballero encantado

RICARDO VIÑALET conoces» (Ortiz, ¿1911 ?: 329). Juana, imbuida de espíritu identitario, refiere a su hermana: "Yo estoy en esta villa donde se meció mi cuna, porque a fuerza de oír hablar de mi raza y de mi linaje ardo en deseos de aprender las hazañas de mis mayores y aquí he venido y me tienes rebuscando pergaminos y cronicones de Indias que sirvan de pasto a las llamas de mi estudioso afán. Apenas encuentro nada, pero sólo el buscarlo ya es alivio en espera de goces que vendrán» (Ortiz, ¿1911?: 330).

Confiesa conocer del delirio de Tarsis porque también a ella la corteja ardientemente, tal cual hace además con el resto de las hermanas: «iHabrase visto sultán! Chica, ¡como se conoce que la sangre mora le bulle en las venas...!» (Ortiz, ¿1911?: 331). El donjuanesco primo no admite rivales, y ella no se sorprende por «toda la ojeriza que Carlitos le guarda a Sam, como por aquí llamamos al vecino» (Ortiz, ¿1911?: 331). Admite cierta simpatía por él, aun siendo también cortejador impenitente, ya que éste reúne cualidades distintas a Carlitos.

Aquí don Fernando procede a una evaluación de las diferencias entre ambos, que no pudieran entenderse descontextualizadamente. La España derrotada, caduca, inculta, analfabeta y pretenciosa era incapaz de reconquistar a América. Sobre el punto ya se ha tratado. Sólo desarrollándose pudiera establecer con Hispanoamérica relaciones de igualdad, respeto y beneficio mutuo. Mas la retórica panhispanista necesitaba llamar la atención acerca del peligro representado por Estados Unidos en lo cual, si bien -como se ha dicho- estaba implícita una actitud oportunista, no se equivocaba.

Fernando Ortiz entendió que una vía de prosperidad para la nación cubana sería factible, si se lograban nexos adecuados con ese país. Deseaba que Cuba pudiera emplear, en su necesario desenvolvimiento, posibilidades que se abrirían a tenor de vínculos con Estados Unidos.

Quizás haya sustentado entonces una consideración demasiado benevolente; tal vez en esos primeros años de república ilusoria no caló del todo en la esencia del pujante imperio, y pudo hasta concederle resquicios de bondad. Cierto es que ya diferentes voces se alzaban frente a la codicia yanqui, también lo es que, más tarde en su vida, ya Ortiz no se llamó a engaño, como lo prueban sus acciones y sus textos.

No quede, sin embargo, la idea de un hombre deslumbrado ni contemporizador con afán imperialista alguno, ni siquiera en 1910, ese 4 de julio en que Juana le escribe a América Andina. Ella sabe de tres conceptos diferentes: la hermana, el vecino y el pretendiente. En El caballero encantado y la moza esquiva, en el resto de los materiales que integran $L a$ reconquista... y en muchos otros de ese período, don Fernando aquilató las actitudes procedentes de Washington en notable medida de su raigal esencia ${ }^{8}$.

Si Juana Antilla aconseja a América Andina de este modo: «Paliquea cuanto quieras con Carlos y hasta entretente con sus romanticismos, que no es malo mirar hacia atrás cuando sabemos mirar firmes hacia adelante; pero guárdate de permitirle irreverentes dichos, ni menos osadías comprometedoras" (Ortiz, ¿1911: 333), está delineando su posición ante el panhispanismo.

También quedará formulada la que asume ante el otro peligro. Expresa: «Así haré yo, si bien, naturalmente, más apegada que tú a mi amigo Sam por necesidades de más honda gratitud y próxima vecindad. Si por esto oyes decir a Carlos que he vendido mi honor, dile que miente, que pura sigo mi vivir honrado, alta y firme la mirada en el porvenir; angustiosa por la inexperiencia de mis pocos años, pero, resuelta a morir antes que retroceder un paso» (Ortiz, ¿1911 ?: 333).

Patriótico, digno, insobornable desde la otredad cubana frente a España y a Estados Unidos, esta versión libre de una novela es mucho más: constituye declaración identitaria y lección de ella. En última instancia, es grito del derecho a ser ante cualquier intento de absorción.

He aquí un modelo de re-escritura interpretativa sobre un texto literario, inducido por los misteriosos vasos comunicantes que fluyen entre la vida y el arte.

He aquí, de igual modo, el trazado de un destino histórico.

\section{BIBLIOGGRAFÍA Y REFERENCIAS}

AINSA, F. (1986): Identidad cultural de Iberoamérica en su narrativa, Editorial Gredos, Madrid, 591, págs. 
BLY, P.A. (1979): «Sex, egotism and social regeneration in Galdós El caballero encantado», Hispania, University of Cincinnati, U.S.A., The American Association of Teachers of Spanish and Portuguese, Inc., Vol. 2, March, Núm. 1, págs. 20-29.

BUENO, S. (1995): Aspectos literarios en la obra de Fernando Ortiz, conferencia pronunciada el 5 de octubre de 1995 en la Fundación La Naturaleza y el Hombre, inédita.

FRANCO, J.L. (1975): «A manera de Prólogo a la segunda edición de Los negros esclavos de Fernando Ortiz», Editorial de Ciencias Sociales, La Habana, págs. 9-11.

GARCÍA-CARRANZA, A. (1970): Bio-bibliografía de Fernando Ortiz, Instituto Cubano del Libro, La Habana, 250 págs.

- (1994): Fernando Ortiz. Suplemento, Biblioteca Nacional José MARTÍ, La Habana, 63 págs.

IBARRA, J. (1985): Un análisis sicosocial del cubano: 1898-1925, Editorial de Ciencias Sociales, La Habana.

MARTÍNEZ VILLENA, R. (1923): «Prólogo a En la tribuna: discursos cubanos, de Fernando Ortiz», tomo I, Imprenta El Siglo XX, La Habana, págs. VII-XVI.

MULLEN, E.J. (1987). «Los negros brujos: A Reexamination of the Text», Revista Cuban Studies, Center for Latin American Studies, University of Pittsburgh Press, Pittsburgh, págs. 111-129.

NOVÁS CALVO, L. (¿1949?): "Cubano de tres mundos». En: Miscelánea de estudios dedicados a Fernando Ortiz por sus discípulos, colegas $y$ amigos, Vol. II, García, S.A., La Habana, 1956, págs. 1133-1141.

ORTIZ, F. (1895): Principi i prostes. Folleto de artículos de costumbres en dialecto menorquín, Ciudadela, Imp. Fábregas, 56 págs.

- (1901): Base para un estudio de la llamada reparación civil. Memoria para optar de doctor en Derecho, Librería de Victoriano Suárez, Madrid, 110 págs.

- (1905): Las simpatías de Italia por los mambises cubanos; documento para la bistoria de la Independencia de Cuba, Marsella, 72 págs.

- (1906): Los negros brujos. Apuntes para un estudio de etnologia criminal. Hampa Afro-Cubana. Carta-prólogo de Cesare
Lombroso, Editorial América, Madrid, ¿1917?, 406 págs.

- (1908): Para la agonografía española; estudio monográfico de las fiestas menorquinas, con un prólogo por Juan Benejam, Imprenta La Universal, La Habana, 41 págs.

- (1909): Los mambises Italianos; apuntes para la historia cubana, Imprenta Cuba y América, La Habana, 64 págs.

- (1910a): El caballero encantado y la moza esquiva. Versión libre y americana de una novela española de Benito Pérez Galdós, Imprenta La Universal, La Habana, paginación varia.

- (1910b): La reconquista de América; reflexiones sobre el panbispanismo, Librería P. Ollendorff, París, 352 págs.

- (1910c): Las rebeliones de los afrocubanos, La Habana, 112 págs.

- (1913a): Entre cubanos: psicología tropical, prólogo de Julio Le Riverend, $2^{a}$ edición, Editorial de Ciencias Sociales, La Habana, 1987, 126 págs.

- (1913b): La Identificación dactiloscópica. Informe de policiologia y de derecho público, seguido de las instrucciones técnicas para la práctica de la identificación y del decreto orgánico $N^{o} .1173$ de 1911, Imprenta La Universal, la Habana, 282 págs.

- (1914): Seamos boy como fueron ayer. Discurso leido el día 9 de enero de 1914 en la Sociedad Económica de Amigos del País, Imprenta La Universal, La Habana, 13 págs.

- (1915): La filosofía penal de los espiritistas; estudio de filosofía jurídica, Imprenta La Universal, La Habana, 126 págs.

- (1916): Los negros esclavos. Tomado de la primera edición: Hampa Afrocubana: Los negros esclavos. Estudio sociológico y de derecho público. A la edición se le han adicionado las notas encontradas en un ejemplar de Los negros esclavos perteneciente al archivo del autor, depositado en el Instituto de Historia de la Academia de Ciencias de Cuba. Además se le han agregado ilustraciones que aparecían en la edición original. Prólogo de José Luciano Franco, Editorial de Ciencias Sociales, La Habana, 1975, 525 págs.

- (1917a), Bases para la organización internacional de la solidaridad de los Estados ante la delincuencia. Informe leído ante la
De cómo Fernando Ortiz supo hallar una moza esquiva para cierto caballero encantado RICARDO VINAALET 
Segunda Sesión del Instituto Americano de Derecho Internacional, celebrada en La Habana en enero de 1917, Imprenta La Universal, La Habana, 8 págs.

- (1917b): Italia y Cuba. Publicado por acuerdo del Comité Cubano Pro Italia, La Habana, 32 págs.

- (1919), La crisis política cubana. Sus causas y remedios. Resumen de un libro que ya no se escribirá, Imprenta La Universal, La Habana, 22 págs.

- (1922), Historia de la arqueología indocubana, Imprenta El Siglo XX, La Habana, 107 págs.

- (1923a): En la tribuna: discursos cubanos. Recopilación y prólogo por Rubén Martínez Villena, dos tomos, Imprenta El Siglo XX, La Habana, tomo I: 196 págs.; tomo II: 236 págs.

- (1923b): «El Dr. De la Torre y la crisis cultural». En su: En la tribuna: discursos cubanos, tomo II, Imprenta El Siglo XX, La Habana.

- (1923c): Un catauro de cubanismos; apuntes lexicográficos, Colección de Libros y Documentos Inéditos o Raros, Vol. 4, La Habana, 270 págs.

- (1924a): La filosofía penal de los espiritistas; estudio de filosofía jurídica, Biblioteca Jurídica de Autores Españoles y Extranjeros, Vol. 66, Ed. Reus, Madrid, 144 págs.

- (1924b): Glosario de afronegrismos; con un prólogo de Juan M. Dibigo, Imprenta El Siglo XX, La Habana, 554 págs.

- (1924c): La decadencia cubana; conferencia de propaganda renovadora pronunciada en la Sociedad Económica de Amigos del País la noche del 23 de Febrero de 1924, Imprenta La Universal, La Habana, 32 págs.

- (1926a): Proyecto de Código Criminal Cubano (Libro Primero o Parte General). Ponencia oficial con un proemio del autor, un juicio de Enrique Ferri y un apéndice con los primeros comentarios, Librería Cervantes, La Habana, 168 págs.

- (1926b): El derecho Internacional en el nuevo proyecto de código criminal cubano, Imprenta El Siglo XX, La Habana, 20 págs.

De cómo Fernando Ortiz supo hallar una moza esquiva para cierto caballero encantado

RICARDO VIÑALET
Washington, 5 de mayo de 1927», Revista Bimestre Cubana, Vol. XXII, julio-agosto, Núm. 4, la Habana, págs. 585-592.

- (1927b): «Las relaciones económicas entre los Estados Unidos y Cuba. Discurso en la American Chamber of Commerce of $\mathrm{Cu}$ ba, el 22 de junio de 1927», Revista Bimestre Cubana, Vol. XXII, julio-agosto, Núm. 4, La Habana, págs. 574-584.

- (1929): «Ni racismos ni xenofobias», $R e-$ vista Bimestre Cubana, Vol. XXIV, Núm. 1, enero-febrero, La Habana, págs. 6-19.

- (1936): "Cómo pensaba yo hace treinta años», Revista Ultra, Vol. I, Núm. 2, agosto, La Habana, págs. 167-172.

- (1940): «Cuba es un ajiaco», La Nueva Democracia, Nueva York, Núm. 11, noviembre.

- (1946): El engaño de las razas, Editorial de Ciencias Sociales, $2^{a}$ edición, La Habana, 441 págs.

- (1955): «El Panhispanismo», Revista Bimestre Cubana, Vol. LXX, Núm. 1, enerodiciembre, La Habana, págs. 55-59.

- (1996): Fernando Ortiz y la cubanidad. Selección y prólogo de Norma Suárez, Colección La Fuente Viva, Fuildación Fernando Ortiz, Ediciones Unión, la Habana, 43 págs.

RIVEREND, J.L. (1987): «Prólogo a la segunda edición de Entre cubanos: psicología tropical, de Fernando Ortiz, Editorial de Ciencias Sociales, La Habana, págs. VXIII.

Pérez Galdós, B. (1909): El caballero encantado. Edición, prólogo, bibliografía general y bibliografía sobre «El caballero encantado», de Julio Rodríquez Puértolas, Ediciones Cátedra, Madrid, 1977, 345 págs.

- (1909): «El caballero encantado». En: Obras completas de [...], Aguilar, Madrid, tomo VI, 1951, págs. 223-343. (F.C. Sainz de Robles tuvo a su cargo la introducción, biografía, notas y censo de personajes galdosianos en este edición).

ROVIRA, J.C. (1992): Identidad cultural y literatura. Antología de pensamiento bispanoamericano, tomo VII, Instituto de Cultura Juan Gil-Albert y Comisión V Centenario, Generalitat Valenciana, Alicante, 236 págs.

SAIIN DE ROBLES, F.C. (1951): «Nota preliminar a El caballero encantado». En: 
Obras completas de Benito Pérez Galdós, tomo VI, Aguilar, Madrid, pág. 221-223.

SCHULMAN, L. (1996): «Introducción a The Autoblography of a Slave. A Bilingual Edition. Introduction and modernized version by Ivan A. Schulman. Transiated by Evelyn Picon Garfield. Latin American Literature and Culture Series, Wayne University Press, Detroit, 135 págs.

UNAMUNO, M. de (1996): Epistolario americano (1890-1936). Edición, introducción y notas de Laureano Robles, Ediciones Universidad de Salamanca, 306 págs.
VIÑALET, R. (1984): Temas de literatura española, tomo II, Editorial Pueblo y Educación, La Habana, 336 págs.

- (1996a): "Entre cubanos y el regeneracionismo", Revista La Gaceta de Cuba, La Habana, Año 34, Núm. 2, marzo-abril, págs. 27-29.

- (1996b): «De Miguel de Unamuno a Fernando Ortiz, dos cartas presumiblemente inéditas», Revista La Gaceta de Cuba, La Habana, Año 34, Núm. 6, noviembre-diciembre, págs. 40-41. 